\section{ABSTRACT}

The goal of this study was to explore (a) the attitudes and behavior of members of the Special Care Dentistry Association (SCDA) who self-identified as treating patients with Autism Spectrum Disorders (ASD) and (b) the relationship between their professional attitudes and behaviors concerning these patients.

Data were collected from 75 SCDA members who responded to an anonymous web-based survey on the SCDA website. The majority of respondents liked to treat children and adults with ASD (57\%/56.9\%). They treated approximately nine patients with ASD in an average week. The more they liked to treat children with ASD, the more patients with ASD they treated $(r=$ $.313 ; p=.018$ ), and the more accommodations to overcome problems with communication, social interactions and aversion to change they made $(r=.404$; $p<.001$ ).

Providers' attitudes concerning patients with ASD were quite positive and correlated with professional behavior concerning these patients. Future research should explore whether improving attitudes towards providing care for special needs patients could increase professional behavior and thus contribute to reducing the access to care problems these patients face.

KAY WOBDS\# oral health care, autism, ASD, attitudes, special needs patients, behavior management

\title{
Treating patients with Hutism Spectrum Disorder—SCDA members' attitudes and behavior
}

\author{
Taryn N. Weil, BS; ${ }^{1}$ Robert A. Bagramian, DDS, DrPH; ${ }^{2}$ \\ Marita Rohr Inglehart, Dr. phil. habil..**
}

\begin{abstract}
${ }^{1}$ Dental Student in the School of Dentistry, University of Michigan, Ann Arbor, Michigan; ${ }^{2}$ Professor of Dentistry, Department of Periodontics and Oral Medicine, School of Dentistry, University of Michigan, Ann Arbor, Michigan; ${ }^{3}$ Associate Professor of Dentistry, Department of Periodontics and Oral Medicine, School of Dentistry \& Adjunct Associate Professor of Psychology, Department of Psychology, College of Literature, Science and Arts, University of Michigan, Ann Arbor, Michigan.

*Corresponding author e-mail: mri@umich.edu
\end{abstract}

Spec Care Dentist 31(1): 8-17, 2011

\section{Introduction}

Autism Spectrum Disorder (ASD) is a group of developmental disorders that includes autistic disorder, Asperger syndrome, and pervasive developmental disorder-not otherwise specified. ${ }^{1-6}$ These disorders have similar symptoms, but differ in the severity, time of onset and exact nature of the symptoms. ${ }^{1,2,4,7-10}$ The symptoms that characterize ASD are communication issues, impairment in social interactions, aversion to change and restricted, repetitive behaviors. ${ }^{1-5,8-16}$ The prevalence rates for ASD in the U.S. have been estimated to range from at least 2.75 per 1,000 to 7.6 per 1,000 children. $6,10,11,17-20$ While ASD is approximately four times more likely to affect males than females, $, 1,5,16,17$ there are no differences in the prevalence rate as a function of the patients' ethnic/racial or socioeconomic background. ${ }^{1}$

When children and adults with ASD need dental health care services, they might encounter an access to care problem. ${ }^{6,21-24}$ This fact was well described in the first U.S. Surgeon General's Report on oral health that was published in 2000.24 This report showed that patients with special needs, including those with ASD, have disproportionately larger amounts of oral disease and problems with access to dental care. ${ }^{24}$ One potential issue contributing to the access to care problems of patients with ASD could be that the characteristics of their disorder-namely their problems with communication and social interactions, their aversion to change and their restricted and repetitive behavior-create challenges for dental care providers during these patients' dental visits. Concerning problems with communication, it is important to understand that $25-40 \%$ of children with ASD do not have verbal communication skills. ${ }^{25-27}$ In addition, those patients with ASD who are able to verbally communicate may have speech that is echoic (repeated from another person's speech), ${ }^{7-9,13,26,28,29}$ or scripted (from a favorite television program or video)..$^{7-9,29}$ A substantial proportion of these patients also have problems with language understanding. ${ }^{7,10,12,16,27}$ All of these communication issues can lead to many problems in a dental setting. For example, providers might have difficulties understanding what patients with ASD are experiencing during their dental treatment. Patients with ASD may not be able to communicate that they experience pain or are uncomfortable, and the 
patients' frustration resulting from this inability might result in their display of inappropriate or challenging behavior.

Concerning the patients' problems with social interactions, dental providers might notice that persons with ASD might not engage in eye contact or other forms of interactions and potentially have difficulties relating to other people. ${ }^{11,13-15,29}$ In a dental office, this characteristic may cause frustration for the provider, as the patient with ASD may not look at them or respond when the provider is giving them necessary instructions. The patients' higher level of anxiety ${ }^{8,10,13,14}$ could also contribute to challenges providers encounter when treating these patients. Given the tendency of these patients to display repetitive behavior or be restricted in their behavior, and to have an aversion to change, a visit to a dental office can be challenging. Such a visit is not a normal part of the daily routine of patients with ASD and therefore might elicit negative behaviors from these patients. In addition, patients with ASD sometimes have heightened sensory perceptions to smells, sounds, or tastes. ${ }^{2,8,27,30}$ Dental procedures can therefore be quite challenging for these patients because they introduce these patients to an array of new sounds, smells, and tastes that may overwhelm patients with ASD and tax their abilities to cope with the demands of the dental visit. ${ }^{10,14,31}$

Given these unique characteristics of patients with ASD and the resulting challenges for dental care providers, it might be useful to understand how providers who provide care for patients with ASD cope with these challenges.

This study collected data from members of the Special Care Dentistry Association (SCDA) who self-identified as providing care for patients with ASD and asked them to describe their professional attitudes, behavior, and experiences when providing care for these patients.

It was interesting to analyze which challenges these providers encountered and which specific behavior management strategies they used in response. An analysis of whether these challenges and behaviors fall into the three categories of ASD specific problems might help to gain a better understanding of these issues. For example, practices related to overcoming communication challenges with patients with ASD could be the use of visual aids $7,10,32$ and behavior shaping with rewards ${ }^{10,14}$; practices related to overcoming social relations problems could be to rely on the social support system of these patients by-for example-communicating with their parents before a dental appointment ${ }^{7,10,27}$ or having parents accompany their children into the dental operatory; ${ }^{10,27,33}$ aversion to change and new stimuli could potentially be countered by offering familiarization visits, ${ }^{7,8,10,15,27,29,34,35}$ bringing a transitional object such as a child's favorite video or music $C D$ to the appointment, 8,10 or using the tell-show-

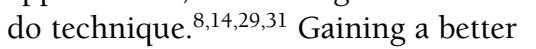
understanding of the professional attitudes and behavior of dental care providers who treat patients with ASD might provide other providers with a better understanding of the behavior management techniques that can be useful in these interactions.

In addition to analyzing the respondents' attitudes and professional behaviors separately, it is also interesting to explore the relationships between the providers' attitudes and behavior. Psychological research such as the studies by Ajzen and Fishbein ${ }^{36,37}$ showed that attitudes can be excellent predictors of behavior. Their theory stated that attitudes and norms in a situation, along with the motivation to comply with those norms, govern behavioral intentions. Behavioral intentions then predict the actual behavior in a given situation. It could therefore be expected that the more positive providers' attitudes are towards patients with ASD, the more likely they would be to provide care for these patients-which in turn could result in an increased expertise in this area.

In summary, the objectives of this research were to explore the professional attitudes and general and specific behaviors of members of the SCDA who self-identified as treating patients with ASD, and also the relationship between these professional attitudes and their behavior when treating patients with ASD.

\section{Methods}

This study was approved by the Institutional Review Board (IRB) for the Health Sciences at the University of Michigan (\#HUM00025463).

\section{Participants}

An email was sent by the Special Care Dentistry Association (SCDA) administration to all SCDA members informing them about the study and asking those members who treat patients with ASD to respond to a web-based survey. A total of 75 SCDA members responded. However, because only a subgroup of the 789 SCDA members provided care for patients with ASD and were therefore eligible to respond to the survey, it was difficult to determine the correct response rate. Approximately equal numbers of male (49\%) and female (51\%) respondents answered. They ranged in age from 28 years to 85 years (mean age $=49$ years).

\section{Procedure}

Data were collected with a web-based survey that was posted by the SCDA on the SCDA website. Three recruitment emails were sent by the SCDA list serve administrator to the 789 SCDA members. The email asked the members to respond to the survey if they had professional experiences concerning patients with ASD which of course limited the number of providers who were eligible to respond. A total of 75 members self-identified and responded to the anonymous web-based survey by accessing it through a link in the recruitment emails.

\section{Materials}

The survey assessed the respondents' background and practice characteristics as well as professional attitudes and behavior concerning providing care for patients with ASD. The questions concerning the respondents' attitudes and specific behavior management techniques when treating patients with ASD were a revised set of questions that had 


\begin{tabular}{|c|c|}
\hline Background characteristics & Responses \\
\hline \multicolumn{2}{|l|}{ Are you male or female? } \\
\hline Male & $49.3 \%$ \\
\hline Female & $50.7 \%$ \\
\hline How old are you? & $\begin{array}{l}\text { Mean = } 49 \text { years; } \\
\text { SD = } 10.88 \text { Range: } 28-85\end{array}$ \\
\hline \multicolumn{2}{|l|}{ What is your ethnicity/race? } \\
\hline African American/Asian American & $4.1 \% / 9.5 \%$ \\
\hline European American/Other & $83.8 \% / 2.7 \%$ \\
\hline \multicolumn{2}{|l|}{ Practice characteristics } \\
\hline \multicolumn{2}{|l|}{ What is your educational background? } \\
\hline DDS/RDH & $83 \% / 17 \%$ \\
\hline \multicolumn{2}{|l|}{ Specialty education } \\
\hline GPR/AEGD/Specialty & $27 \% / 7 \% / 35 \%$ \\
\hline How long have you practiced your profession? & $\begin{array}{l}\text { Mean }=23 \text { years; } \\
\text { SD = } 11.1 \text { Range: } 1 \text { to } 61 \text { years }\end{array}$ \\
\hline \multicolumn{2}{|l|}{ Describe your practice location: } \\
\hline Rural/Small town/Moderate-sized city & $5 \% / 5 \% / 31 \%$ \\
\hline Suburb/Large city & $20 \% / 39 \%$ \\
\hline \multicolumn{2}{|l|}{ Describe your employment situation: } \\
\hline Solo Practice/Partnership/Group Practice & $16 \% / 12 \%$ \\
\hline Associateship/Academic Appointment & $3 \% / 20 \%$ \\
\hline Salaried Employee: HMO/Hospital/Other & $3 \% / 12 \% / 21 \%$ \\
\hline Percentage of time spent in: & Mean (SD) \\
\hline Office Practice/Dental School & $47 \%(42.04) / 18 \%(33.44)$ \\
\hline Hospital/HMO or other prepaid clinic & $25 \%(33.95) / 4 \%(17.19)$ \\
\hline Outreach, nursing or group home/Administration & $5 \%(18.10) / 4 \%(17.53)$ \\
\hline What percentage of your patient population is of: & Mean (SD) \\
\hline High SES/Average SES & $18 \%(22.98) / 31 \%(24.20)$ \\
\hline Low SES & $53 \%(32.54)$ \\
\hline What percentage of your patients are covered by: & Mean (SD) \\
\hline Medicaid/Private pay & $48 \%(36.58) / 21 \%(24.89)$ \\
\hline Insurance & $25 \%(24.40)$ \\
\hline How many hours per week do you work? & $\begin{array}{l}\text { Mean = } 39 \text { hours; } \\
\text { SD = 9.95; Range: } 16 \text { to } 65 \text { hours }\end{array}$ \\
\hline
\end{tabular}

been pretested and then used in an earlier study with general and pediatric dentists. ${ }^{39}$ These questions were developed by matching the behavior management strategies used with all pediatric patients with the three sets of to describe the biggest challenges they faced when providing dental care for these patients, and to share their best practices with other dental care providers who wished to treat patients with ASD.

\section{Statistical analyses}

The data were analyzed with SPSS (Version 17.0). ${ }^{38}$ Descriptive statistics such as frequencies, percentages and means were provided to give an overview of the findings. Pearson correlation coefficients were computed to analyze the relationships between the professional attitudes and general and specific professional behaviors concerning patients with ASD. A $p$ value of $\leq .05$ was considered statistically significant.

\section{Results}

The first step in the analyses was to describe the background of the respondents (see Table 1 for an overview). As mentioned briefly, $49 \%$ of the respondents were male and $51 \%$ female. Their average age was 49 years and they ranged in age from 28 years to 85 years (SD: 10.88). The majority of the respondents were European American (84\%), while 10\% were Asian American, and 4\% African American. Most of the respondents had a dental degree (83\%), while $17 \%$ had a dental hygiene degree. In addition, $27 \%$ of the respondents reported that they had completed a GPR, $7 \%$ had completed an AEGD, and 35\% had specialty training. The respondents had practiced an average of 23 years (range: $1-61$ years; $\mathrm{SD}=11.1$ ). While most respondents' practices were either in a large city (39\%) or moderate-sized city $(31 \%), 20 \%$ practiced in the suburbs, only $5 \%$ in a rural area, and 5\% in a small town. Only $16 \%$ of the respondents reported having a solo practice, $12 \%$ practiced in a partnership or group practice, and 3\% had an associateship. However, $20 \%$ of the providers had an academic appointment and 36\% were salaried employees, either in an HMO (3\%), a hospital setting (12\%), or in another setting $(21 \%)$. The majority of the respondents' time was spent in an office practice (on average: $47 \%$ ), in a 
Table 2. Description of attitudinal responses.

\begin{tabular}{|l|l|l|l|l|}
\hline Professional Attitudes $^{\text {a }}$ & 1 \& 2 & 3 & 4 \& 5 & Mean \\
\hline $\begin{array}{l}\text { My professional education prepared me well } \\
\text { for treating patients with ASD. }\end{array}$ & $47.7 \%$ & $15.4 \%$ & $36.9 \%$ & 2.86 \\
\hline I like to treat children with ASD. & $13.9 \%$ & $29.2 \%$ & $57 \%$ & 3.75 \\
\hline I like to treat adults with ASD. & $16.9 \%$ & $26.2 \%$ & $56.9 \%$ & 3.60 \\
\hline $\begin{array}{l}\text { My dental team members are comfortable } \\
\text { treating patients with ASD. }\end{array}$ & $10.8 \%$ & $16.9 \%$ & $72.3 \%$ & 3.95 \\
\hline $\begin{array}{l}\text { My dental team members are knowledgeable } \\
\text { about treating patients with ASD. }\end{array}$ & $15.4 \%$ & $26.2 \%$ & $58.4 \%$ & 3.74 \\
\hline $\begin{array}{l}\text { Patients with ASD are often unable to tolerate } \\
\text { dental treatment. }\end{array}$ & $33.9 \%$ & $30.8 \%$ & $35.4 \%$ & 3.03 \\
\hline $\begin{array}{l}\text { Financial compensation for treating autistic } \\
\text { pts is inadequate. }\end{array}$ & $13.9 \%$ & $13.8 \%$ & $72.3 \%$ & 4.02 \\
\hline aThe answers were given on a scale from "1" = "disagree strongly" to "5" = "agree strongly". \\
\hline
\end{tabular}

hospital (25\%), or in a dental school (18\%). Additionally, $4 \%$ of their time was spent in an HMO or other prepaid clinic, $5 \%$ in an outreach situation, such as in a nursing home or a group home, and $4 \%$ in administration. The respondents worked an average of 39 hours per week, but the responses ranged from 16 hours to 65 hours per week (SD: 9.95). The majority of their patients were from lower socioeconomic backgrounds (low SES: 53\%; average SES: $31 \%$; high SES 18\%) and on average, $48 \%$ of their patients were covered by Medicaid (private pay: $21 \%$; private insurance: $25 \%$ ).

Table 2 shows an overview of the attitudinal responses of the providers. The answers to the Likert type items were given on a scale from " 1 " = "disagree strongly" to " 5 " = "agree strongly." Nearly half of the respondents disagreed or disagreed strongly with the statement "My professional education prepared me well for treating patients with ASD" (48\%) and only $37 \%$ agreed or strongly agreed with this statement. Despite these rather negative evaluations of how well their dental education had prepared them for treating patients with ASD, the majority of the respondents agreed or agreed strongly with the statements "I like to treat children with ASD" (57\%) and "I like to treat adults with ASD" (57\%), and indicated that their dental team members were comfortable (72\%) and knowledge- able (58\%) when treating patients with ASD. About a third of the providers disagreed/disagreed strongly with the statement "Patients with ASD are often unable to tolerate dental treatment" (34\%), while another third responded neutrally to this statement (31\%) and the last third agreed/strongly agreed with this statement (35\%). A majority (72\%) of the providers agreed or agreed strongly with the statement "Financial compensation for treating autistic patients is inadequate" and only 14\% disagreed or disagreed strongly with this statement.

The dental care providers' professional behavior concerning the care for patients with autism consisted of analyzing the responses to four sets of questions. Table 3 shows an overview of the responses to these questions. The first set of questions was concerned with the specialists' general behavior, namely the number of patients with special needs, ASD, and other developmental disorders that they treated in an average week, and whether they treated patients on the whole autism disorder spectrum. The answers to these questions showed that these respondents treated on average 63 patients in a week of which 29 patients had special needs, 9 patients had an ASD, and 18 patients had other developmental disabilities. Most of the respondents $(87 \%)$ treated patients from the whole autism spectrum.
The second and third question sets were concerned with behaviors specific to treating patients with ASD. The content of these questions was divided according to the three categories of ASD defining characteristics, which were communication challenges, social relations problems, and an aversion to change and new situations, and repetitive and restricted behaviors. The respondents indicated first if they provided certain accommodations for patients with ASD concerning these three groups of challenges in their office. Then they also responded to the questions about how often they used such techniques on a scale with " 1 " = "never," " 2 " = "sometimes," and " 3 " = "often." To overcome communication challenges, $59 \%$ of the respondents reported using special visual aids for communication with patients with ASD and 92\% used these visual aids sometimes or often. Most of the specialists responded that they used other techniques to overcome communication issues at least "sometimes" or "often." For example, $97 \%$ used behavior shaping with rewards, $97 \%$ used positive reinforcement with words, $97 \%$ used tell-show-do, and 97\% used tell-showfeel sometimes or often.

In order to overcome social relations problems, $78 \%$ of the specialists gave the parents special instructions before the child's treatment, and $91 \%$ allowed the parents to accompany their child into the operatory. Many of the dental care providers let the patients with ASD observe other children "sometimes" $(48 \%)$ or "often" $(40 \%)$ or they let them observe their parents (sometimes: $39 \%$ or often: $29 \%$ ).

To overcome issues with aversion to change and new situations, $71 \%$ of the respondents offered familiarization visits before a first appointment for their patients with ASD, $80 \%$ offered special scheduling arrangements for these patients, and $52 \%$ had a special office setup to meet the needs of patients with ASD. However, the majority of these providers did not have a television set in the waiting room $(63 \%)$ or in the operatory $(71 \%)$, and $52 \%$ of the specialists did not allow the parents to bring 
Table 3. Description of professional behavior related to treating patients with ASD.

\begin{tabular}{|c|c|c|c|c|}
\hline General behavior & \multicolumn{4}{|l|}{ Mean } \\
\hline \multicolumn{5}{|l|}{ In an average week, how many patients } \\
\hline Do you treat? & \multicolumn{4}{|c|}{63 patients } \\
\hline Are special needs patients? & \multicolumn{4}{|c|}{29 patients } \\
\hline Have autism spectrum disorder (ASD)? & \multicolumn{4}{|c|}{9 patients } \\
\hline Have other developmental disabilities? & \multicolumn{4}{|c|}{18 patients } \\
\hline Do you treat patients from the whole ASD spectrum? & \multicolumn{2}{|c|}{ Yes: $\mathbf{8 7 \%}$} & \multicolumn{2}{|c|}{ No: $13 \%$} \\
\hline Sum of special accommodations used & \multicolumn{2}{|c|}{ Mean: 6.34} & \multicolumn{2}{|c|}{ Range: 0 to 10} \\
\hline \multicolumn{5}{|l|}{ ASD specific behavior: } \\
\hline 1. Practices related to overcoming communication challenges & \multicolumn{2}{|c|}{ Yes } & \multicolumn{2}{|c|}{ No } \\
\hline Special visual aids for communication & \multicolumn{2}{|c|}{$59 \%$} & \multicolumn{2}{|c|}{$41 \%$} \\
\hline \multirow[t]{2}{*}{ Rewards at the end of child's visit } & \multicolumn{2}{|c|}{$90 \%$} & \multicolumn{2}{|c|}{$10 \%$} \\
\hline & Never & Sometimes & Often & Mean \\
\hline Visual aids & $8.1 \%$ & $46.8 \%$ & $45.2 \%$ & 2.37 \\
\hline Behavior shaping with rewards & $3.2 \%$ & $43.5 \%$ & $53.2 \%$ & 2.50 \\
\hline Positive reinforcement with words & $3.1 \%$ & $7.8 \%$ & $89.1 \%$ & 2.86 \\
\hline Tell - Show - Do & $3.1 \%$ & $10.9 \%$ & $85.9 \%$ & 2.83 \\
\hline Tell - Show - Feel & $3.1 \%$ & $15.6 \%$ & $81.3 \%$ & 2.78 \\
\hline 2. Practices related to overcoming social relations problems & \multicolumn{2}{|c|}{ Yes } & \multicolumn{2}{|c|}{ No } \\
\hline Special instructions to parents before treatment & \multicolumn{2}{|c|}{$78 \%$} & \multicolumn{2}{|c|}{$22 \%$} \\
\hline \multirow{2}{*}{ Parent can accompany their children in the operatory } & \multicolumn{2}{|c|}{$91 \%$} & & $\%$ \\
\hline & Never & Sometimes & Often & Mean \\
\hline Letting them observe other children & $12.7 \%$ & $47.6 \%$ & $39.7 \%$ & 2.27 \\
\hline Letting them observe their parent's dental treatment & $32.3 \%$ & $38.7 \%$ & $29.0 \%$ & 1.97 \\
\hline 3. Practices related to overcoming aversion to change and new situations & & es & & lo \\
\hline Familiarization visits before the first appointment & & $\%$ & & $\%$ \\
\hline Special scheduling arrangements & & $\%$ & & $\%$ \\
\hline Special office set-up & & $\%$ & & $\%$ \\
\hline TV set in waiting area & & $\%$ & & $\%$ \\
\hline TV set in operatory & & $\%$ & & $\%$ \\
\hline Parent can bring child's favorite video & & $3 \%$ & & $\%$ \\
\hline & Never & Sometimes & Often & Mean \\
\hline Desensitization efforts & $4.7 \%$ & $28.1 \%$ & $67.2 \%$ & 2.63 \\
\hline General behavior management strategies: & Never & Sometimes & Often & Mean \\
\hline 1. Pharmacological techniques & & & & \\
\hline Nitrous oxide inhalation & $36.5 \%$ & $42.9 \%$ & $20.6 \%$ & 1.84 \\
\hline Oral sedation & $29.7 \%$ & $53.1 \%$ & $17.2 \%$ & 1.88 \\
\hline General anesthesia & $25.4 \%$ & $47.6 \%$ & $27.0 \%$ & 2.02 \\
\hline 2. Nonpharmacological techniques & & & & \\
\hline Hand-over-mouth technique & $93.4 \%$ & $4.9 \%$ & $1.6 \%$ & 1.08 \\
\hline Papoose Board / physical restraints & $46.9 \%$ & $43.8 \%$ & $9.4 \%$ & 1.63 \\
\hline Having dental assistant(s) restrain child & $42.9 \%$ & $54.0 \%$ & $3.2 \%$ & 1.60 \\
\hline Having parent restrain child & $23.8 \%$ & $68.3 \%$ & $7.9 \%$ & 1.84 \\
\hline 3. Refer to specialists & & & & \\
\hline Refer to specialists & $50.8 \%$ & $42.4 \%$ & $6.8 \%$ & 1.56 \\
\hline
\end{tabular}


their child's favorite video to the office. To overcome the patients' issues with aversion to change and new situations, these providers used desensitization efforts "sometimes" (28\%) or "often" (67\%). The respondents used an average of 6.34 different accommodations when providing care for patients with ASD (Range: from 0 to 10 different accommodations).

In addition to asking questions about behavior related to the three sets of ASD specific challenges, a final set of questions asked the providers to indicate how often they used pharmacological behavior management strategies such as nitrous oxide inhalation, oral sedation and general anesthesia, and general non pharmacological behavior management techniques such as hand-over-mouth, and different types of restraints.

Alternatively, few respondents used pharmacological behavior techniques (nitrous oxide: $37 \%$; oral sedation: $30 \%$; general anesthesia: $25 \%$ ) to control behavior. However, $21 \%$ used nitrous oxide often, $17 \%$ used oral sedation often, and $27 \%$ used general anesthesia often when treating patients with ASD. Evaluation of the data showed that the majority of the providers (93\%) never used the hand over mouth technique, and that only few providers used restraints often (Papoose board: $9 \%$; having a parent restrain the child: $8 \%$; having a dental assistant restrain a child: $3 \%$ ). Finally, $51 \%$ of the respondents never referred patients with ASD to specialists, $42 \%$ sometimes referred these patients, and only $7 \%$ referred often to specialists.

The final set of analyses was concerned with the correlations between the respondents' professional attitudes and behavior concerning patients with ASD. Table 4 provides the findings concerning the relationships between the providers' directly related attitudes (as measured with statements such as "I like to treat children with ASD" and "I like to treat adults with ASD") and related professional behaviors such as the number of accommodations for patients with ASD and practices related to overcoming challenges these patients would potentially create. An evaluation of the findings show that the better the respondents felt prepared to treat patients with ASD, the more often they used specific behavior management techniques aimed at overcoming communication issues, such as behavior shaping with rewards $(\mathrm{r}=.316$; $p=.012)$ and positive reinforcement with words $(\mathrm{r}=.261 ; p=.037)$, and also aimed at overcoming aversion to change and problems with new situations such as desensitization efforts $(r=.339$; $p=.006)$. In addition, the quality of their dental education was also significantly correlated with the frequency with which they used pharmacological techniques such as nitrous oxide $(\mathrm{r}=.424$; $p<.001)$ and oral sedation $(r=.261$; $p=.037$ )

The relationships between how much the providers liked to treat children and adults with ASD and their behavior was also explored. An evaluation of the data showed that the more the providers liked to treat children with ASD, the more patients under 16 years of age $(r=.251$; $p=.047)$, the more patients with ASD $(\mathrm{r}=.313 ; p=.018)$, and the more patients with other developmental disabilities they treated in an average week $(r=.260 ; p=.048)$. In addition, the more they liked to treat children with ASD, the more they used techniques aimed at overcoming the three sets of challenging characteristics by using more ASD specific accommodations overall $(\mathrm{r}=.404 ; p<.001)$ as well as techniques aimed at overcoming communication challenges (such as tell - show - do: $\mathrm{r}=.304 ; p=.015$; tell - show - feel: $\mathrm{r}=.428 ; p<.001$ ); techniques aimed at overcoming social interaction challenges (such as letting the patient observe other children: $\mathrm{r}=.404 ; p=.001$; or their parent during their dental treatment: $\mathrm{r}=.331 ; p=.008)$; and overcoming aversion to change (such as desensitization efforts: $\mathrm{r}=.289 ; p=.021$ ).

However, there were no significant relationships between how much the respondents liked to treat adults with ASD and their behavior.

Two questions were concerned with how comfortable and knowledgeable the providers thought their staff members were with patients with ASD. The more the providers used specific techniques addressing challenges of patients with ASD such as tell - show - do $(r=.380$; $p=.002)$ and tell - show - feel $(\mathrm{r}=.382$; $p=.002)$, and letting these patients observe their parent's dental treatment $(\mathrm{r}=.251 ; p=.049)$, the more they reported that their staff was comfortable with these patients. The more accommodations the providers offered for patients with ASD ( $\mathrm{r}=.300 ; p=.019)$, and the more often they used techniques aimed at overcoming challenges encountered with patients with ASD (such as using visual aids: $\mathrm{r}=262 ; p=.040$; tell show - do: $\mathrm{r}=.412 ; p=.001 ;$ tell show - feel: $\mathrm{r}=.447 ; p<.001 ;$ and desensitization efforts: $\mathrm{r}=.347 ; p=.005$ ), the more the providers felt that their staff was knowledgeable about treating patients with ASD.

\section{Discussion}

In this study, the respondents self identified as being providers of care for patients with ASD so it was possible to analyze their characteristics as well as which best practices they used.

An evaluation of these data showed clearly that providers who treat patients with ASD differed in their practice characteristics, their attitudes and their educational preparation from other general dentists. Further evaluation of the data showed that the SCDA respondents were less likely to be in traditional solo practices and were more likely to have a salaried position in which they provided care for higher percentages of patients on Medicaid or for patients from lower socioeconomic backgrounds. The fact that they were more likely to practice in large and moderate cities and less likely to work in small towns and rural areas should also be noted, because it explains why patients with ASD living in rural areas or small towns might have an even more difficult time when trying to access dental care services.

Another characteristic of these providers was that their attitudes towards providing care for children and adults with ASD were quite positive. A comparison of the responses of these SCDA 
Table 4. Correlations between professional attitudes and general and ASD specific professional behavior.

\begin{tabular}{|c|c|c|c|c|c|c|c|}
\hline Professional behavior: & \begin{tabular}{|l|} 
My prof. \\
education \\
prepared me \\
well $^{\mathrm{a}}$
\end{tabular} & $\begin{array}{l}\text { I like to treat } \\
\text { children } \\
\text { with ASDa }\end{array}$ & $\begin{array}{l}\text { I like to treat } \\
\text { adults with } \\
\text { ASD }^{\mathrm{a}}\end{array}$ & $\begin{array}{l}\text { My staff } \\
\text { is comfort- } \\
\text { able }^{\mathrm{a}}\end{array}$ & $\begin{array}{l}\text { My staff has } \\
\text { knowledge }^{\text {a }}\end{array}$ & $\begin{array}{l}\text { Patients } \\
\text { with ASD } \\
\text { unable to } \\
\text { tolerate }^{\mathrm{a}}\end{array}$ & $\begin{array}{l}\text { Financial } \\
\text { compen- } \\
\text { sation }^{a}\end{array}$ \\
\hline \multicolumn{8}{|l|}{ In an average week: } \\
\hline How many patients do you treat? & .141 & $.211+$ & .055 & .067 & .153 & .081 & -.168 \\
\hline How many patients are $<16$ years old? & -.057 & $.251^{*}$ & -.057 & .091 & .186 & .084 & -.119 \\
\hline How many are special needs patients? & .174 & .171 & .174 & .104 & .186 & .053 & .023 \\
\hline How many patients with ASD? & -.173 & $.313^{*}$ & .058 & .102 & $.252+$ & .156 & .176 \\
\hline $\begin{array}{l}\text { How many of your patients have other } \\
\text { developmental disabilities? }\end{array}$ & $-.323^{*}$ & $.260^{*}$ & .059 & .064 & .144 & -.006 & .071 \\
\hline $\begin{array}{l}\text { Number of accommodations for } \\
\text { patients with ASD }\end{array}$ & .197 & $.404^{* * *}$ & .042 & $.216+$ & $.300^{*}$ & -.046 & .044 \\
\hline \multicolumn{8}{|l|}{$\begin{array}{l}\text { Practices related to overcoming } \\
\text { communication challenges }{ }^{b}\end{array}$} \\
\hline Behavior shaping with rewards & $.316^{*}$ & $.225+$ & -.080 & .171 & $.307^{*}$ & -.124 & $.241+$ \\
\hline Visual aids & .175 & .160 & .087 & .134 & $.262^{*}$ & -.118 & .107 \\
\hline Positive reinforcement with words & $.261^{*}$ & $.213+$ & -.019 & $.340^{* *}$ & $.419^{* * *}$ & -.204 & $.306^{*}$ \\
\hline Tell - Show - Do & $.241+$ & $.304^{*}$ & .015 & $.380^{* *}$ & $.412^{* * *}$ & $-.219+$ & $.292^{*}$ \\
\hline Tell - Show - Feel & $.238+$ & $.428^{* * *}$ & .138 & $.382^{* *}$ & $.447^{* * *}$ & $-.229+$ & $.225+$ \\
\hline \multicolumn{8}{|l|}{$\begin{array}{l}\text { Practices for overcoming social } \\
\text { relations problems }{ }^{b}\end{array}$} \\
\hline Letting them observe other children & .144 & $.404^{* * *}$ & .057 & .180 & .207 & .044 & .041 \\
\hline Letting them observe their parents & .176 & $.331^{* *}$ & .156 & $.251^{*}$ & .182 & .089 & -.064 \\
\hline \multicolumn{8}{|l|}{$\begin{array}{l}\text { Practices for overcoming aversion } \\
\text { to change / new situations }{ }^{b}\end{array}$} \\
\hline Desensitization efforts & $.339^{* *}$ & $.289^{*}$ & .049 & .202 & $.347^{* *}$ & -.090 & .112 \\
\hline \multicolumn{8}{|l|}{ Behavior management strategies: $\mathbf{~}^{\mathbf{b}}$} \\
\hline 1. Pharmacological techniques & \begin{tabular}{|l|} 
My educa- \\
tion \\
prepared me \\
well $^{\mathrm{a}}$
\end{tabular} & $\begin{array}{l}\text { I like to treat } \\
\text { children } \\
\text { with ASDa }\end{array}$ & $\begin{array}{l}\text { I like to treat } \\
\text { adults with } \\
\text { ASD }^{\mathrm{a}}\end{array}$ & $\begin{array}{l}\text { My staff is } \\
\text { comfortable }^{a}\end{array}$ & $\begin{array}{l}\text { My staff } \\
\text { knowledge }^{a}\end{array}$ & $\begin{array}{l}\text { Patients } \\
\text { with ASD } \\
\text { unable to } \\
\text { tolerate }^{\mathrm{a}}\end{array}$ & $\begin{array}{l}\text { Financial } \\
\text { compensa- } \\
\text { tion }{ }^{\mathrm{a}}\end{array}$ \\
\hline Nitrous oxide inhalation & $.424^{* * *}$ & .173 & .152 & $.340^{* *}$ & $.304^{*}$ & .099 & $.248^{*}$ \\
\hline Oral sedation & $.261^{*}$ & .082 & .107 & $.316^{*}$ & $.329 * *$ & .066 & .175 \\
\hline General anesthesia & $.220+$ & $.239+$ & .130 & .191 & .187 & .110 & $.279^{*}$ \\
\hline \multicolumn{8}{|l|}{ 2. Nonpharmacological techniques } \\
\hline Hand-over-mouth technique & -.119 & .006 & .044 & -.043 & -.118 & .070 & -.003 \\
\hline Papoose Board / physical restraints & .138 & $.215+$ & .082 & .157 & .187 & -.018 & .080 \\
\hline Have dental assistant restrain child & .092 & .082 & -.099 & .110 & .068 & -.165 & .004 \\
\hline Have parent restrain child & $.268^{*}$ & .188 & -.167 & $.337^{* *}$ & $.317^{*}$ & $.268^{*}$ & -.129 \\
\hline
\end{tabular}


members with a survey of general dentists in Michigan and a national survey of members of the American Academy of Pediatric Dentistry showed that the attitudes of the SCDA members seemed more positive than those of general or pediatric dentists. ${ }^{39}$ However, it is also noteworthy that significantly more of these experienced SCDA members realized that the financial compensation for treating patients with ASD is inadequate compared to the numbers of general and pediatric dentists. This finding raises the question of whether the SCDA could take on an advocacy role concerning these issues.

Finally, while the responses to the statement "My professional education prepared me well to treat patients with ASD" might not seem utterly positive (mean $=2.86$ on a 5 point scale with $1=$ disagree strongly), they were significantly more positive than the responses of the general dentists in Michigan $($ mean $=1.53)$ or the pediatric dentists nation wide (mean $=1.75) .{ }^{39}$ This finding should alert dental and dental hygiene educators to the importance of developing curricula that provides clinical care for patients with special needs. ${ }^{40,41}$ Because respondents in this study had self-identified as providing care for patients with ASD, it was possible to analyze which best practices they used when treating their patients. These respondents did not only treat children with ASD in an average week, they also treated others with developmental disabilities and special needs and also used a significant number of accommodations when providing care for patients with ASD. The providers' responses were categorized according to the three groups of problems that are characteristic for patients with ASD, namely problems with communication, social interactions and aversion to change and preference for restricted and repetitive behavior. In this context it is mandatory to state that while patients with ASD have similar symptoms, they differ quite significantly in the severity, time of onset and exact nature of their symptoms , $2,4,7-10$; therefore, they cannot be treated similarly. The respondents in this study were very aware of the special accommodations they used to allow them to care for patients with ASD.

Finally, it is important to note that pharmacological behavior management strategies were used by quite a number of providers (see Table 3 for exact percentages). Comparative studies describing various pharmacological approaches by Asahi et al. $^{42}$ and by Pisalchaiyong et al. ${ }^{43}$ as well as some older studies, ${ }^{13,29,44}$ discuss various protocols in dentistry. Educating future dental care providers about these pharmacological techniques should contribute to the use of these drugs for their patients.

Our results suggest how more dental care providers could be motivated to provide care for these patients with ASD. In our study, we found significant relationships between the quality of dental education and the types of professional behaviors reported and that professional attitudes were clearly related to professional behavior. These findings should alert dental and dental hygiene educators to the importance of providing positive experiences for future dental care providers during their training, which should include treating patients with ASD and other special health care needs. Although these correlations suggested that only part of the variance was explained, it should be noted that the indicators of interest were of a psychological/behavioral nature. In the social sciences, correlations higher than the ones found here are relatively rare because psychological processes are usually determined by numerous factors, each of which only contributes partially to the phenomenon under investigation.

Finally, the study had several limitations. By asking SCDA members who treat patients with ASD to respond to this survey, it became unclear how to determine the response rate because not all SCDA members are necessarily providing care for patients with ASD. Nevertheless, the sample size of 75 respondents was relatively small and therefore only allowed a first exploration of these issues. More sophisticated statistical techniques such as modeling could not be used. In addition, by focusing on
SCDA members, only a subgroup of dental care providers who have experiences with treating patients with ASD were surveyed. Additional information about best practices could potentially be gained from a survey of ADA members in general who provide this type of care.

\section{Conclusions}

SCDA members who self identified as providing care for patients with ASD were more likely to have salaried positions and less likely to own a solo practice compared to U.S. dental care providers in general. ${ }^{45}$ In addition, they were less likely to practice in rural settings or small towns, making it potentially more difficult for patients with ASD in these locations to access dental care services.

The majority of the respondents had quite positive attitudes towards providing care for patients with ASD and considered their dental team members as knowledgeable and comfortable when treating these patients. A large majority indicated that the financial compensation for treating these patients was inadequate.

The data concerning the respondents' professional behavior supports the conclusion that they should be considered as "specialists" in regard to providing care for patients with ASD, because they not only treated a relatively large number of these patients in an average week, but they also used accommodations to cope with the characteristic challenges of these patients.

With the question as to what these results can contribute to reducing the access to care problems that patients with ASD face, two findings could be of interest. First, the positive relationship between the professional attitudes of the caregiver and their patients: Dental educators should reflect about how more clinical dental education could increase the comfort level-and thus potentially the attitudes-of future dental care providers which in turn might affect their willingness to treat patients with ASD. Second: Specific programs might contribute to educating future dental 
care providers in a way that they have the tools to accommodate the needs of these patients-which also might affect their willingness to provide care for these underserved patients.

\section{Acknowledgements}

We would like to thank the leadership of the Special Care Dentistry Association for their support for this study, and Kim Eskew for her help with posting this survey on the Special Care Dentistry Association website and sending recruitment emails to the members of this association. This research was supported by NIH Training Grant T32-DD007057, which provided research support for the first author.

\section{References}

1. Centers for Disease Control and Prevention. Autism. Overview. Available at: http://www.cdc.gov/ncbddd/autism/index. html [Accessed October 12, 2010].

2. American Psychiatric Association. Diagnostic and Statistical Manual of Mental Disorders, 4th ed., Text Revision (DSM-IV- TR). Washington, DC: American Psychiatric Publishing; 2000.

3. Barbaresi WJ, Katusic SK, Voigt RG. Autism: a review of the state of the science for pediatric primary health care clinicians. Arch Pediatr Adolesc Med 2006;160:1167-75.

4. Dover CJ, Le Couteur A. How to diagnose autism. Arch Dis Child 2007;92:540-5.

5. Loo CY, Graham RM, Hughes CV. The caries experience and behavior of dental patients with autism spectrum disorder. J Am Dent Assoc 2008;139:1518-24.

6. Thikkurissy S, Lal S. Oral Health Burden in Children with Systemic Diseases. Dent Clin North Am 2009;53:351-7.

7. Dougall A, Fiske J. Access to special care dentistry, part 2. Communication. Br Dent J 2008;205:11-21.

8. Green D, Flanagan D. Understanding the autistic dental patient. Gen Dent 2008;56:167-71.

9. Johnson CP, Myers SM, American Academy of Pediatrics Council on Children with Disabilities. Identification and Evaluation of Children with Autism Spectrum Disorders. Pediatrics 2007;120:1183-215.
10. Raposa KA. Behavioral management for patients with intellectual and developmental disorders. Dent Clin North Am 2009;53:359-73.

11. Bertrand J, Mars A, Boyle C, Bove F, YearginAllsopp M, Decoufle P. Prevalence of autism in a United States population: the Brick Township, New Jersey, investigation. Pediatrics 2001;108:1155-61.

12. Marshall J, Sheller B, Williams BJ, Mancl L, Cowan C. Cooperation predictors for dental patients with autism. Pediatr Dent 2007; 29:369-76.

13. Kamen S and Skier J. Dental management of the autistic child. Spec Care Dentist 1985; 5:20-3.

14. Klein U, Nowak AJ. Autistic disorder: a review for the pediatric dentist. Pediatr Dent 1998;20:312-7.

15. Dean JA, Avery DR, McDonald RE. McDonald and Avery's Dentistry for the Child and Adolescent, 9th ed. Maryland Heights, MI: Mosby/Elsevier; 2011: 475.

16. Bailey AJ, Rutter ML. Autism. Sci Prog 1991; 75:389-402.

17. Fombonne E. Epidemiological surveys of autism and other pervasive developmental disorders: an update. J Autism Dev Disord 2003;33:365-82.

18. Yeargin-Allsopp M, Rice C, Karapurkar T, Doernberg N, Boyle C, Murphy C. Prevalence of autism in a US metropolitan area. J Am Med Assoc 2003;289:49-55.

19. Rutter M. Incidence of autism spectrum disorders: changes over time and their meaning. Acta Paediatr 2005;94:2-15.

20. Kopycka-Kedzierawski DT, Auinger P. Dental needs and status of autistic children: results from the National Survey of Children's Health. Pediatr Dent 2008; 30:54-8.

21. Koneru A, Sigal MJ. Access to dental care for persons with developmental disabilities in Ontario. J Can Dent Assoc 2009;75:121-121j.

22. Newacheck P, Hung YY, Wright KK. Racial and ethnic disparities in access to care for children with special health care needs. Ambula Pediatr 2002;2:247-54.

23. Owens PL, Kerker BD, Zigler E, Horwitz SM. Vision and oral health needs of individuals with intellectual disability. Ment Retard Dev Disabil Res Rev 2006;12:28-40.

24. US Department of Health and Human Services. Oral Health in America: A Report of the Surgeon General. NIH Publication
00-4713. National Institute of Dental and Craniofacial Research, National Institutes of Health, 2000:7.

25. Dawson $G$, Watling R. Interventions to facilitate auditory, visual and motor integration in autism: a review of the evidence. J Autism Dev Disord 2000;30:415-21.

26. Rapin I. The autistic-spectrum disorders. N Engl J Med 2002;347:302-3.

27. Waldman HB, Perlman SP, Wong A. Providing dental care for the patient with autism. J Calif Dent Assoc 2008;36:662-70.

28. Prizant BM, Duchan JF. The functions of immediate echolalia in autistic children. J Speech Hear Disord 1981;46:241-9.

29. Kopel HM. The autistic child in dental practice. ASDC J Dent Child 1977, 44: 302-9.

30. Burkart N. Understanding and managing the autistic child in the dental office. Dent Hyg 1984;58:60-3.

31. Friedlander AH, Yagiela JA, Paterno VI, Mahler ME. The neuropathology, medical management and dental implications of autism. J Am Dent Assoc 2006;137:1517-27.

32. Pilebro C, Backman B. Teaching oral hygiene to children with autism. Int J Paediatr Dent 2005;15:1-9.

33. Klein U, Nowak AJ. Characteristics of patients with autistic disorder (AD) presenting for dental treatment: a survey and chart review. Spec Care Dent 1999;19:200-7.

34. Luscre DM, Center DB. Procedures for reducing dental fear in children with autism. J Autism Dev Disord 1996;26:547-56.

35. Swallow JN. The dental management of autistic children. Br Dent J 1969;126:128-31.

36. Ajzen I, Fishbein M. Attitudinal and normative variables as predictors of specific behaviors. In: Fazio RH, Petty, RE, editors. Attitudes: Their Structure, Function and Consequences. New York: Psychology Press; 2008:425-443.

37. Ajzen I and Fishbein M. The influence of attitudes on behavior. In: Albarracin D, Johnson BT, Zanna MP, editors. The Handbook of Attitudes. Mahwah, NJ: Lawrence Erlbaum Associates Publishers; 2005:173-221.

38. SPSS, Inc. SPSS, Version 17. Chicago, IL: SPSS Inc., 2008.

39. Inglehart MR, Ramaswami $N \&$ Feigal RJ. Pediatric dentists and autistic patients - who treats how? J Dent Res 2004;83 (Spec Iss A):1497. 
40. Dehaitem MJ, Ridley K, Kerschbaum WE, Inglehart MR. Dental hygiene education about patients with special needs: a survey of US programs. J Dent Educ 2008;72: 1010-19.

41. Dao LP, Zwetchkenbaum S, Inglehart MR. General dentists and special needs patients: does dental education matter? J Dent Educ 2005;69:1107-15.
42. Asahi $\mathrm{Y}$, Kubota K, Omichi S. Dose requirements for propofol anaesthesia for dental treatment for autistic patients compared to intellectually impaired patients. Anaesth Intensive Care 2009;37:70-73.

43. Pisalchaiyong T, Trairatvorakul C, Jirakijja J, Yoktarnonda W. Comparison of the effectiveness of oral diazepam and midazolam for the sedation of autistic patients during dental treatment. Pediatr Dent 2005;27: 198-206.

44. Davila JM, Jensen OE. Behavioral and pharmacological dental management of a patient with autism. Spec Care Dent 1988;8:58-60.

45. Weil TN, Inglehart MR. General and pediatric dentists' professional attitudes and behavior concerning patients with autism—does dental education matter? J Dent Educ 2010;74:1294-307. 